\title{
Academic Achievement and Life Satisfaction Among Medical Students with Forced Medical Parental Choice
}

\author{
Sadia Firdous \\ University of Lahore \\ Rabia karim \\ Lecturer at University of Lahore \\ Roofen Julious \\ Lecturer at Aligarh Nursing College Lahore \\ Sheeba Saqib \\ Nursing Supervisor at the Indus Hospital Lahore
}

\begin{abstract}
The purpose of the present study was to determine the relationship between academic achievement and life satisfaction and whether forced parental choice mediated the relationship between these constructs. It was hypothesized that academic achievement and life satisfaction would have a significant relation and that parental choice would mediate this association. The study used a co relational research design. The sample size of the study was 200 including 100 males and 100 females' selected using purposive sampling. Pearson product moment correlation, independent sample t test, regression and mediation analysis were used. The results have shown that there is a significant relationship between academic achievement and life satisfaction. It was also found that forced parental choice mediated the relationship between academic achievement and life satisfaction. However, there were no gender differences among medical students on these constructs.
\end{abstract}

Key words: Academic achievement, Life satisfaction, Medical students, Forced Parental Choice

DOI: $10.7176 / \mathrm{JHMN} / 62-17$

Publication date:May $31^{\text {st }} 2019$

\section{Introduction}

Most recently, there has been an increasing amount of influence of parental choice on medical choice. There are a number of factors which influence a wide range of health sciences among professionals. A number of studies have been done on how parental choices influence student's perceptions about their life and their level of academic achievement. However, there is a gap in literature on this area in Pakistan in relevance to academic achievement and life satisfaction. Research on the role of parental choice in influencing student's academic achievement and life satisfaction have revealed a number of findings (Jiang, Huebner \& Hills, 2013; Jenkins, Belanger, Connally, Boals \& Durón, 2013).

It has been found in a number of studies that the influence of forced parental choice is highly negative and leads to long term psychological and career problems among young adults. On the other hand, some studies have found that the impact is positive for students as educated parents have a better understanding about the career choices for their children that are going to lead to long term benefits and advantages (Casas, et al, 2013; Jiang, Huebner \& Hills, 2013; Jenkins, Belanger, Connally, Boals \& Durón, 2013).

In relevance to the construct of life satisfaction, a wide range of studies have been done in the domain of positive psychology. These studies have dealt with the core components and factors that characterize a "good life". It is also concerned with how individuals living conditions can be improved. There is also evidence to show that the determinants of life satisfaction among young adults. For students, career choice is characterized by marked levels of emotional upheaval as well as high level of exposure to a wide range of risks and opportunities. Furthermore, these individuals have been exposed to a great number of challenges as well as stressors (Hofmann, Luhmann, Fisher, Vohs \& Baumeister, 2014; Varela, Zimmerman, Ryan, Stoddard, Heinze \& Alfaro, 2017).

It is a fact that students in the present times have been faced increased levels of pressure in order to achieve success in academic domains, especially in terms of careers that are highly specific and selective like medical schools, engineering schools and other related factors. Earlier studies did not find correlations among these variables (Hofmann, Luhmann, Fisher, Vohs \& NBaumeister, 2014; Varela, Zimmerman, Ryan, Stoddard, Heinze\& Alfaro, 2017).

There has also been criticism that these studies have ignored the role played by demographic factors. It has also been found that the role of moderating variables such as school environment, parenting styles, 
socioeconomic background, gender and age are currently lacking. For this reason, it is critical to conduct a detailed exploration on this area by focusing on the role played by demographic factors (Varela, Zimmerman, Ryan, Stoddard, Heinze \& Alfaro, 2017).

It has also been found that for medical students, there are a number of factors that influence career choices of students. There are an infinite number of learning experiences that impact career choice. However, one major factor in this regard is parental choice. It has been found that in a large number of cases, parental choice is forced upon students. This is mainly because of the fact that parents are the ones who finance the education of their children in a large number of cases.

This fact is equally true for both developed and developing regions. Also, parental choice is less important for those students who are able to finance their own education. Secondly, pursuing a profession in the domain of medicine is a tough decision. For medical students, parental choice becomes important and a determining factor at times when they are not able to take a decision on their own.

Since 1980s, family therapists as well as career counselors and other individuals have unearthed important and critical information about the importance of parental choice of careers for their children. Even though adolescents begin to display independence in terms of their education at a young age, still most of them continue to show their dependence on their parents during the span of their young adulthood that spans from 18 to 25 years of age. With these background researches into focus, it is important to assess how parental choice influences academic achievement and life satisfaction among medical students.

\section{Academic Achievement}

An individual's choice (as contemplated in technique, staying power, and stage of interest) regarding instructional topics whilst competence is judged towards a general of overall performance or excellence (Di-Perna \& Elliott, 1999; McClelland, 1961).

Academic achievement can also be defined as the extent to which a student or teacher or an institution has been able to achieve their short and long term career goals and objectives. Cumulative GPA, completion of a degree and other related factors represent the academic achievement of students. Research has shown that academic achievement is commonly measured through the use of examinations and continuous levels of assessments but there is no general agreement on this area (Wigfield \& Eccles, 2002).

\section{Theories of Academic Achievement}

Academic achievement theory is as follows

\section{Self Determination Theory}

Despite the fact that instructional determination has viewed from a large number of conceptual views tons of the present studies managed with the help of self-dedication concept. Self-determined ideas are a detailed theoretical set up which explains worldwide, contextual, and unique stimuli. Deciand Ryan (1985, 2000b) differentiated extrinsically influenced behaviors as a means to applicable give up from intrinsically inspired behaviors completed for inner satisfaction and delight (Vallerand, 1997).

Extrinsic motivation reflects to do something or pursue a task rather than considering it duty. An Innate stimulus refers to do an activity for personal satisfaction and pleasure (Lepper, Corpus, \& Iyengar, 2005).

\section{Life Satisfaction}

Life satisfaction is defined as being a measure of wellbeing and is used to convey how people convey their emotions. It can be accessed through the use of mood, satisfaction with their relations, satisfaction with goal achievement, self-concepts and other related measures. Another definition is that life satisfaction is the level of favorable orientation that people tend to have about their social, personal, psychological and occupational life. Another definition is that life satisfaction is a specific and focused measure of economic standing, social wellbeing as well as academic wellbeing for students (Mallard, Lance \& Michalos, 2017).

Research has shown that life satisfaction can reflect the level of positive experiences individuals have about their living conditions (Jayawickreme, Tsukayama \& Kashdan, 2017). These experiences have the ability to cause motivation among people in order to be able to pursue their goals and objectives. It has been found that there are two forms or kinds of emotions that might influence the manner in which people form perceptions about their lives.

It is also important to ponder that optimism and hope encompass core cognitive processes that are usually focused on how successfully people are able to achieve their goals and objectives. According to the researched conducted by Martin Seligman, the more happy individuals are, the higher is their probability to achieve life satisfaction. So it can be said that happier individuals have a greater tendency to experience increased levels of life satisfaction (Jayawickreme, Tsukayama \& Kashdan, 2017). 
Wellbeing is a broad concept that encompasses the psychological, subjective, health related behaviors and as well as social dimensions. Psychological well-being that involves various important aspects such as selfacceptance, the sense of purpose in life, autonomy, the capability to cope multifaced environment, the establishment of worthy attachment to others, the recreation of significant goals and the continued improvement and growth as individual (Ryff, 1995).

Another definition views the psychological wellbeing as a dynamic construct that includes subjective, psychological and as well as social aspects of different behaviors. It can also be viewed as the level of satisfaction, happiness and dedication that people experiences in their lives. Another definition views psychological wellbeing includes six core aspects such as acceptance of self, self-growth, sense of purpose in life, environmental mastery and perfection, autonomy and positive relations with others in life. It is crucial for the individual to satisfy the demands of these dimensions to achieve optimal levels of psychological functioning (Schmitt, Branscombe, Postmes \& Garcia, 2014).

\section{Theories of Life Satisfaction}

Followings are the theories of Life satisfaction:

\section{Whole Life Satisfaction Theory}

The theory states that level of life satisfaction among individuals based on the scores in following dimensions. These dimensions include: level of self-acceptance, Relations with others, environmental mastery, autonomy in performing activities of life, sense of purpose in life and level of personal growth. An individual's who score high in these dimensions indicate the higher level of psychological wellbeing (Jayawickreme, Tsukayama \& Kashdan, 2017).

Individuals who show positive feelings and emotions towards these dimensions are always happy and satisfied with their lives. People should always show positive feelings and emotions towards these dimensions Rocke, 2016).

Happiness is defined as being the average level of wellbeing and satisfaction an individual has in his or her life (Singh \& Jha, 2008). It is also referred to as the level or extent to which an individual experiences positive emotional conditions and states. Research has shown that happiness is an important and significant functionality of life and determines success of individuals (Agid et al., 2008).

It encompasses three core components including frequency of happiness, degree of happiness and absence of varying forms of negative feelings. It has been found that happiness leads to positive and productive outcomes in life (Stewart, Watson, Clark, Ebmeier \& Deary, 2010). There are a number of theoreticians believe that happiness and wellbeing are related to higher levels of marital satisfaction (Argyle, 2009).

The relationship has been found and confirmed that significant and important predictors of general sense of happiness and wellbeing (Stack \& Eshlemen, 1998). Such relationships have been confirmed by numerous multicultural findings and studies. It is critical to note that happiness and health are related to one another. Also, individuals who show these tendencies are happier in comparison to the rest of the individuals (Loue \& Sajatovic, 2008).

\section{Authentic happiness theory}

The Authentic happiness theory of life satisfaction explains that happiness is important construct that can be explained in three most important dimensions. These dimensions include: 1 . experiencing the positive emotions 2. Meaning 3. Higher levels of accomplishment and engagement (Proyer, Gander, Wellenzohn \& Ruch, 2016).

The theory argues that high levels of psychological wellbeing based on how much happy a person is and how much authentic is his happiness. In other words, happiness should be important for all individuals and it must be occurred persistently. A person must be scored high on above mentioned dimensions which include experiencing the positive emotions, purpose and meaning, higher level of accomplishment, engagement and relationship to achieve high level of psychological wellbeing. The researches on this theory revealed that in case of serious health problems, individuals experience trouble in acquiring the levels of authentic happiness (Proyer, Gander, Wellenzohn \& Ruch, 2016).

\section{Hedonism Theory}

This theory explains that life satisfaction is the evaluation of subject. Individuals who enjoy the positive feelings of happiness or pleasure always score high on psychological wellbeing. They are also capable to decrease or minimize the pain when they experience. This theory states that an individual must be taken part in activities that increases or maximize the happiness and pleasure and decreases the pain (Seligman \& Royzman, 2003).

The theory also states that life satisfaction is a measure that is achieved effectively when one starts to focus on the positive sides of life and stop focusing on the negative. 
After a thorough analysis of the theoretical perspectives on the constructs of life satisfaction and academic achievement, it is important to explore the literature on this area.

\section{Welfares Theory}

Research has shown that wellbeing has an important role to play in any form of welfare theories and perspectives. The theory states that the ultimate goal of human life should be to provide support to other individuals. Individuals who support others, tend to engaged in problem solving with them, provide knowledge and guidance to them are able to strive and achieve higher levels of development and advancement. Also, the theory emphasizes the need for using universal moral principles and values. The idea is that human morality is shaped by the presence and use of moral values that are based on providing support for all humanity without discrimination on the basis of caste, color and creed (Raz, 1986, p. 164).

\section{Literature Review}

To my knowledge numerous researches and findings support a significant, positive connection among life satisfaction and academic achievement for students (Lent, Brown, \& Larkin, 1987; Locke, Frederick, Lee, Bobko, 1984; timber \& Locke, 1987). Lent, Brown, Larkin (1987) stated that those, who have excessive selfefficacy scores and high scholastic aptitudes, have a tendency to attain more, favorable academic outcomes than those who have lower self-efficacy and aptitude rankings. A examine on self-efficacy and its effect on instructional attainment, the findings of Zimmerman, Bandura, and Martinez-Pons (1992), is another incredible studies in this subject matter.

The authors gift a conceptual model of self-regulated motivation and educational mastering which illustrates the tested causal paths of how perceived self-efficacy for instructional success in turn impacts their personal goals and grade fulfillment. Carrying out such goals no longer only requires the talents needed to accomplish that, but the beliefs of self-efficacy to use the ones skills well. Self-efficacy ideals also have an effect on college students' motivation with the aid of the level of attempt they positioned closer to conducting dreams and their resilience to disasters.

As Bandura (1993) stated "student beliefs of their skills to grasp academic topics expect their subsequent educational attainments." students' instructional development is affected by their self- efficacy to manipulate their gaining knowledge of and grasp course topics. Researchers have shown that instructional social influence that include cognitive techniques models, aim settings, attribution comments, wonderful incentives, and verbalizing project techniques (Bandura, 1993) can decorate a scholar's degree of self-efficacy (Schunk, 1989).

Previous studies have found that parental choice is a predictive of university grades and their level of life satisfaction. Having belief that an individual would carry out successfully in a given direction predicts actual a hit performance in that direction. Lent, Brown and Larkin (1987) discovered "parental choice introduced large precise variance past measures of goal ability and fulfillment in predicting next instructional overall performance and endurance".

Gerdes and Mallinckrodt (1994) explained that those students who achieved good results are more confident about their own abilities and skills to achieve academic success as compare to those students who achieve poor results and withdraws from college. Also, they belonged to backgrounds that were marked by the presence of educated parents who had guided them and had facilitated them to engage in decision making about their career choice.

Crede, Wirthwein, McElvany and Steinmayr (2015) have found that there has been an increase in the emphasis on adolescents and young adult's life satisfaction. Past studies have shown conflicting findings when it comes to documenting the relationship between life satisfaction and academic achievement for students belonging to different fields. The present study focused on the role of parent's choice, parent's education and other related factors in terms of determining the relationship between academic achievement and life satisfaction.

The sample for the study included 411 students belonging to German medical schools. The findings had shown that parental choice, parental education, socioeconomic status and other related factors influence the relationship between academic achievement and life satisfaction. More specifically, educational attainment of parents and the level of influence they have on their children's career choices were significant moderators. It was also found that father's education is more important in terms of predicting academic achievement of their children in comparison to their mother's level of education.

Ferry, Fouad and Smith (2000) had studied the role of family context in terms of impacting career related choice among individuals. Also, the emphasis was on personal, contextual as well as experiential factors in terms of impacting career choice of students. Data for the study was collected from 791 medical students from two universities. Results of the study helped in validation of the findings of some previous studies. It was found that parental encouragement was an important determinant and had a direct effect on the learning experiences of children. 
Age, gender, SES and forced parental choice also predicted academic achievement among students. It was found that forced parental choice lead to low levels of academic achievement among medical students in comparison to parental encouragement that resulted in higher levels of academic achievement for medical students.

Roeser and Peck (2009) had explored the role of self-awareness, meta-cognition, parenting and other demographic factors that influence academic achievement among students. The design of the study was a systematic review. The researchers had used a number of databases such as embase, medline, cinahl and other databases.

A total of 20 studies were selected for the review. The studies selected had highlighted the role of contemplative education and parental measures. The results had shown that promoting met cognitive awareness in contemplative education leads to improved educational attainment in students. Also, parents who forced their children to pursue medical careers without providing them with complete guidance and support negatively impacted academic achievement of students.

It was found that conscious and willful intent of students coupled with parental support is important in terms of influencing the self-esteem of students. It is important to consider that academic performance of students and their sense of academic achievement is determined on the basis of a number of measures including selfefficacy, self-awareness, Meta cognitive awareness etc. These factors have a combined impact on the academic performance and educational attainment of students.

Otoole (2009) had studied the differences in individual patterns of learning and the role of promoting Meta cognition and other positive psychological tendencies in students. Also, the study investigated the importance of parental factors in influencing academic achievement and life satisfaction. The study also analyzed the links between learning and psychological wellbeing. The educational trends have always been changing. It has been established that educational policies, role of teachers, parents and the learning approaches used in educational institutions impact the psychological wellbeing of students. One important factor in this regard is Meta cognitive awareness.

Students who use Meta cognitive awareness and other related competencies more often report higher levels of psychological wellbeing. Also, differences have been seen in terms of the specific learning styles of students. More specifically, students can be classified into different learners. These include: visual learners, tactile learners, aural learners and kinesthetic learners. The findings have shown that students using a combination of different learning styles score better on different measures of psychological wellbeing.

Also, they are able to make an effective use of these strategies at time when they are confident about the level of support from their parents. In addition, Meta cognitive awareness plays a moderating role in terms of determining the relationship between learning and psychological wellbeing.

Redman, Saltman, Straton Young and Paul (2004) studied the determinants of career choices and life satisfaction among medical students. A cross sectional research design was used for the study. The sample for the study included 812 students including 412 women and 400 men. It was found that forced parental choice was more impactful and prevalent for female medical students in comparison to men. It was also found that forced parental choice negatively impacted the relationship between academic achievement and life satisfaction for the students. Another finding was that parental choice provided with support and guidance and keeping in view the interests of their children led to positive effects on life satisfaction and academic achievement.

Sui-Chu and Willms (2006) studied the role of parental involvement in terms of influencing academic achievement among students. The sample for the study included 314 students from college and university settings. Results showed that parental involvement was identified as being an important determinant of academic achievement and life satisfaction among students. It was found that parents who engaged in excessive involvement and forced their children to pursue their own preferential careers negatively impacted their achievement. In comparison, parental involvement that was positive and was focused more on positive support for their children had a positive impact on academic achievement and life satisfaction among their children.

Chak-keung Wong and Jing Liu (2010) had studied the role of parental choice on academic achievement and life satisfaction of students in medical professions. The purpose of the study was on investigating whether the influence of parental choice was positive or negative. The findings had shown that parental choice was high for most of the medical students. Students identified that the financing is done by their parents and it limits their own autonomy.

On the other hand, there were also students who stated that their parents supported their own choices and they were not forced to pursue medical professions by force. However, the findings were mixed. It was found that parental choice alone did not explain the level of academic achievement and life satisfaction among medical students. It was also determined that socioeconomic status, student's academic performance in the past, gender, self-efficacy and past learning experiences of students determined their level of academic achievement.

Zahedani, Rezaee, Yazdani, Bagheri and Nabeie (2016) studied the role of parental involvement and parenting styles on academic achievement and life satisfaction on student's academic achievement. The sample for the study was collected from Shiraz University of Medical Sciences. From 1600 students, 310 were randomly 
selected. Career path questionnaires and Baumarind Parenting Style were used. Findings showed that parents had an important role in identification of the careers for their children and guiding them about which careers are better for them.

However, a number of them lag behind in having a clear understanding about the skills and abilities of their children and the careers best suited for them. Most of the medical students identified that their parents did influence their choices. More than half of them identified that they were pressured to opt for a medical career since the time they had completed their high school education.

The researchers recommended that parental interaction with their children in terms of career choices should be more positive and should be focused on providing support rather than limiting their choices. This leads to negative effects on their academic achievement and also leads to reduction in terms of the level of life satisfaction.

Pinquart (2016) conducted a meta-analysis to focus on how parenting styles, parental choice, age, gender and other related factors influence academic achievement among adolescents and young adults. A wide range of dimensions were strategically analyzed in the current investigation. The Meta analysis focused on 308 empirical studies for associations in relevance to parenting dimensions and styles.

The findings showed that parental responsiveness, behavioral control, autonomy granting and authoritative parenting styles were linked with higher levels of academic performance. Neglectful parenting, forced parental choice, lack of warmth and lack of autonomy had a negative impact on academic achievement of students. The findings also showed moderating effects of child age, ethnicity, and quality of parenting and of other related factors.

Costa and her colleagues (2015) studied the mediating role of parental choice, need satisfaction and parental psychological control on life satisfaction of college students. The researchers had stated that relatively few studies have assessed the mediating roles of parental involvement. The sample size included 289 college students including 150 males and 139 females. The findings showed that parental involvement without provision of autonomy, support and warmth led to negative effects on life satisfaction.

Female students were forced to pursue careers by their parents had low life satisfaction. Similar findings were seen for males as well. It was also found that most college students lack autonomy and decision making in relevance to their career choices. Psychological control and parental involvement were identified as being important mediators of the relationship between academic achievement and life satisfaction of college students.

Aghaei, Behjat and Rostampour (2015) had studied a sample of Iranian male and female high school students. The purpose of the study was to explore the relationship between academic achievement and life satisfaction. The analysis of data had shown that there was a significant gender difference in terms of academic achievement and life satisfaction. Male scored higher than females in relevance to academic achievement. Results also have shown positive relationship between the two constructs. The findings had shown that the development of these measures leads to positive academic and personal outcomes for students.

One survey in this regard was conducted on a sample of 512 students. The gender distribution of the sample was 212 males and 300 females. The participants were assessed for their level of academic achievement. The findings had shown that females scored slightly higher than males in terms of this construct. This finding also shows that females are more dedicated towards academic achievement in comparison to males (Nasel, 2004).

Sugiura (2004) had investigated the concept of academic achievement and life satisfaction. The sample for the study included 127 Japanese college students. Another aim of the study was to explore the gender differences in terms of their academic achievement. They had been asked to complete questionnaires on cognitive styles and academic achievement. The researcher had employed structural equation modeling for developing a structure and a model of academic achievement and life satisfaction.

The results had shown that parental involvement that was positive had helped in reducing worrisome behaviors for both males and females. The study has shown that promoting the level of parenting and providing higher level of support can be helpful in reducing academic problems for students. Also, it was found that men had higher levels of academic achievement in comparison to female students. However, females on the other hand had scored higher in terms of the level of life satisfaction.

Cisheng at al. (2017) had investigated the importance of promoting academic achievement by promoting their spiritual intelligence and through the provision of higher level of parental support. The sample for the study included 156 male and female students studying in different academic settings. They had been asked to complete questionnaire on SI. All participants were presented with the SI promotion program.

After that, post-test assessments were performed. The findings had shown that male participants scored high on spiritual intelligence in comparison to the females. However, the researcher did highlight that Iranian females scored high on spiritual intelligence in comparison to females from US, UK and Russia based on the analysis of secondary sources of information. Those who scored high on spiritual intelligence also scored high in the domain of academic achievement and life satisfaction. 
Wells (2005) had investigated the effectiveness of CBT in promoting Meta cognitive awareness in male and female college students. A sample of 233 students facing psychological and behavioral problems was selected. The results had shown that Meta cognitive training should be provided with special emphasis on a number of areas including activation of Meta cognitive knowledge, monitoring, and suspension of conceptual management and processing, attention oriented flexibility and a de-centered relationship and orientation in terms of cognitive domains through CBT.

The results had shown that the program was effective in terms of promoting the wellbeing, life satisfaction and other related positive mental states. The self-concept of students was also influenced effectively due to the promotion and development of these concepts. It is clear that the study has raised the need of developing training and educational programs for teachers as well as students. The research on this area has shown that there numerous positive educational and psychological outcomes for teachers and students (Wells, 2005).

White (2006) had aimed to study the importance of promoting spiritual intelligence, academic achievement and Meta cognitive skills in college students and to explore the existing gender differences. The core focus of the paper was on how educational leadership in different countries can work to promote programs aimed at promoting the performance of students on these dimensions. Data collection was from the University of California.

It was found that male students who scored high on spiritual intelligence and those men who were engaged in intellectual development showed better mental health facets and academic performance. The researcher had also ascertained the need of developing prescriptive models for establishing the importance of Meta cognitive awareness and spiritual intelligence.

\subsection{Problem Statement}

There are an infinite number of learning experiences that impact career choice. However, one major factor in this regard is parental choice. It has been found that in a large number of cases, parental choice is forced upon students. This is mainly because of the fact that parents are the ones who finance the education of their children in a large number of cases. This fact is equally true for both developed and developing regions. Also, parental choice is less important for those students who are able to finance their own education.

Secondly, pursuing a profession in the domain of medicine is a tough decision. For medical students, parental choice becomes important and a determining factor at times when they are not able to take a decision on their own. Since 1980s, family therapists as well as career counselors and other individuals have unearthed important and critical information about the importance of parental choice of careers for their children.

Even though adolescents begin to display independence in terms of their education at a young age, still most of them continue to show their dependence on their parents during the span of their young adulthood that spans from 18 to 25 years of age. With these background researches into focus, it is important to assess how forced parental choice influences academic achievement and life satisfaction among medical student.

Also, the gap in literature on this area in Pakistan needs to be bridged. There is also limited evidence to show the mediating role of forced parental choice. The present study is going to contribute to exploring this area in a detailed manner.

\subsection{Aims and Objectives}

The aims and Objectives of this study as follows

i. To investigate the association between academic achievement and life satisfaction among medical students via the mediation of parental involvement

ii. To investigate gender differences among medical students in relevance to life satisfaction and achievement

iii. To determine the role of forced parental choice in terms of impacting life satisfaction and academic achievement among medical students

\subsection{Hypotheses}

The hypotheses of this study as follows

i. There would be a significant relationship between academic achievement and life satisfaction among medical students

ii. There would be significant gender differences among medical students in terms of life satisfaction and academic achievement

iii. Forced parental choice would predict academic achievement and life satisfaction among medical students

iv. Forced parental choice would mediate the relationship between academic achievement and life satisfaction 


\subsection{Rational}

To investigate the association between academic achievement and life satisfaction among medical students via the mediation of parental involvement and to determine the role of forced parental choice in terms of impacting life satisfaction and academic achievement among medical students.

\section{Method And Material \\ Research Design \\ Co-relational study design was used to measure the relationship between the variables.}

Target population

The target population was, King Edward Medical College, Allama Iqbal Medical College, University of Lahore, Lahore Medical and Dental College.

Sample size

The sample size for the study was 200 medical students in which include 100 male and 100 females.

Sampling technique

Convenient sampling technique was used to collect data.

Inclusion Criteria

The inclusion criteria for the study,

- $\quad$ Age range of the sample was from 22 to 28 years

- Currently enrolled in medical colleges and were doing their MBBS or BDS.

Exclusion criteria

The exclusion criteria for the study,

- Those who were pursuing other degrees and programs from these institutions.

- Those who are not willing to participate

\section{Instruments:}

The tools used in this study are as follows

\section{Independent variable tool (Academic Motivation Scale AMS)}

Academic Motivation Scale was formulated by Vallerand et al. in 1992, 1993) constructed the AMS with further seven sub dimensions, which includes 3 forms of intrinsic provocation (i.e., expertise, accomplishment, and to experience a stimulation), 3 forms of extrinsic provocation i.e., identified, introverted, and external regulation, and also a motivation. AMS scale has good reliability and validity values which reported alpha values for the AMS ranging between .62-.86 (Vallerand et al., 1992), .70-.86. Scores ranges from 0-65 are termed as low, 65-98 as moderate and 98-196 as highest scores.

\section{Dependent variable tool (Satisfaction with Life)}

Satisfaction with life scale was used with participants to assess individuals on their life satisfaction this construct, a 5 item scale was used. Diener, Emmons, Larsen and Griffin (1985) had developed this scale as a global measure of overall life satisfaction. It is used for measuring and assessing global cognitive judgments of individuals about their lives.

Participants are required to indicate how much they agree or disagree with the items. They are required to answer on a 7 point scale ranging from 7 strongly disagree to 1 strongly agree. The scoring for the scale is done using a pre-defined criterion. A score of 5 to 9 indicates extreme dissatisfaction, 10 to 14 indicates dissatisfied in general, 15 to 19 shows slight dissatisfaction, 20 is a neutral score, 21 to 25 shows slight satisfaction, 26 to 30 is satisfied and 31 to 35 is extremely satisfied. The sample items include "in most ways my life is close to my ideal......" "I am satisfied with my life". The cronbach alpha value for this scale is .87 .

\section{Statistical Analyses}

SPSS (Statistical package for social science) software program version 21.0 was used to analyze the data. Correlation analysis, Linear and stepwise regression analysis was used to predict significant predictors of academic achievement. T-test was used to find out the significant gender differences. Also, mediation analysis was used for the present investigation.

\section{Ethical Considerations}

Following Ethical consideration was kept in mind during conducting the research.

i. Scales were used after the permission of the concerned authorities.

ii. A permission letter which explained the nature and purpose of the research was also issued by the university authorities.

iii. Purpose of the study was also defined to the participants

iv. Written consent form was also taken from the participants.

v. They were given the right to withdraw or decline from the research whenever they want.

vi. It was assured that their information provided by the participants would keep private and personal and would be used for research purpose. 


\section{Results And Data Analysis}

The table 1 shows that $50 \%$ of the participants were males and $50 \%$ were females. In terms of age, about $49.5 \%$ of the participants belonged to the age range of 18 to 24 and about $51.5 \%$ belonged to the age range of 25 to 30 . About $24 \%$ belonged to low SES, $56 \%$ to Middle SES and about $20 \%$ belonged to high SES. In terms of institutional affiliation, $33.5 \%$ belonged to KEMU, $16.5 \%$ belonged to AIMC, $27.5 \%$ belonged to UOL and 22.5 belonged to LMDC.

Frequency Statistics of Demographic Variables of the Sample $(\mathrm{N}=\mathbf{2 0 0})$

Table 1

\begin{tabular}{lcc}
\hline Variables & $f$ & $\%$ \\
\hline Gender & 100 & 50 \\
Male & 100 & 50 \\
Female & & \\
Age & 198 & 49.5 \\
18 to 24 & 202 & 51.5 \\
25 to 30 & & \\
Socioeconomic Status & 48 & 24 \\
Lower & 112 & 56 \\
Middle & 50 & 20 \\
Upper & & \\
Institution & 67 & 33.5 \\
KEMU & 33 & 16.5 \\
AIMC & 55 & 27.5 \\
UOL & 45 & 22.5 \\
LMDC & 200 & 100 \\
Total & & \\
\hline
\end{tabular}

Table 2 shows that the Pearson Product Moment Correlation to find out the relationship between academic achievement and life satisfaction for medical students. The results indicated that there was a significant and strong positive relationship between academic achievement and life satisfaction $(r=.35, p<.01)$. The findings have established that high academic achievement does result in higher levels of life satisfaction among medical students.

Correlation between Academic Achievement (AA) and Life Satisfaction (LS) (N= 200)

Table 2

Variable $\quad I \quad I I$

\section{AA}

$.35 * *$

\section{LS}

Note. ${ }^{* *} p<.01 \mathrm{AA}=$ Academic Achievement, LS= Life Satisfaction

Table 3 shows mean differences between male and females on academic achievement and life satisfaction. The results indicated that there were no significant differences among males and female medical students in terms of their scores on academic achievement and life satisfaction.

Mean Differences on Academic Achievement (AA) and Life Satisfaction (LS) (N=200)

\section{Table 3}

\begin{tabular}{|c|c|c|c|c|c|c|c|c|c|}
\hline \multirow[t]{2}{*}{ Variable } & \multicolumn{2}{|c|}{ 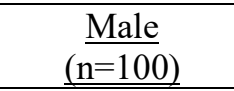 } & \multicolumn{2}{|c|}{$\begin{array}{l}\text { Female } \\
(\mathrm{n}=100)\end{array}$} & \multicolumn{4}{|c|}{$95 \% \mathrm{CI}$} & \multirow[b]{2}{*}{ Cohen's $d$} \\
\hline & $M$ & $S D$ & $\bar{M}$ & $S D$ & $t(198)$ & $P$ & $L L$ & $U L$ & \\
\hline LS & 21.38 & 6.82 & 21.10 & 6.36 & .30 & .76 & -1.15 & 2.12 & 0.02 \\
\hline AA & 68.37 & 13.20 & 66.56 & 13.81 & .96 & .33 & -1.91 & 5.61 & 0.03 \\
\hline
\end{tabular}

Note. $C I=$ confidence interval, $L L=$ lower limit, $U L=$ upper limit. ${ }^{*} p<.05, A A=$ Academic Achievement, $L S=L i f e$ Satisfaction 
Table 4 shows that the Linear regression analysis for prediction of academic achievement. It was found parental choice $(B=.-5.89, p<.05)$ significantly and negatively predicted academic achievement. $R^{2}$ indicates that $4 \%$ variance in academic achievement. This shows that parental choice did not account for majority of the variance. However, the prediction of parental choice was significant, an indication of importance of parental choice in terms of influencing academic achievement among medical students.

\section{Multiple Regression for Forced Parental Choice as Predictors of Academic Achievement among medical} students $(\mathbf{N}=\mathbf{2 0 0})$

Table 4

\begin{tabular}{lcccc}
\hline Variable & $B$ & $S E$ & $B$ & $95 \% C I$ \\
\hline Constant & 75.55 & 2.81 & & {$[69.55,81.11]$} \\
Parental Choice & $-5.89 *$ & 1.93 & -.21 & {$[-9.70,-2.08]$} \\
$r^{2}$ & & & .04 & \\
$F$ & & & 9.29 & \\
$R$ & & & .21 & \\
$* p<.05, \mathrm{CI}=$ Confidence Interval & & &
\end{tabular}

Linear regression analysis was used for prediction of life satisfaction. It was found parental choice $(B=-10.32, p$ $<.05)$ significantly and negatively predicted life satisfaction. $R^{2}$ indicates that $5 \%$ variance in academic achievement. It has been established that parental choice significantly influenced life satisfaction among medical students.

Multiple Regression for Forced Parental Choice as Predictors of Life Satisfaction among medical students $(\mathrm{N}=\mathbf{2 0 0})$

Table 5

\begin{tabular}{lcccc}
\hline Variable & $B$ & $S E$ & $\beta$ & $95 \% C I$ \\
\hline Constant & 44.72 & 4.38 & & {$[37.07,53.36]$} \\
Parental Choice & $-10.32 *$ & 3.20 & -.22 & {$[-16.64,-4.00]$} \\
$r^{2}$ & & & .05 & \\
$F$ & & & 10.37 & \\
$R$ & & & .22 & \\
\hline
\end{tabular}

${ }^{*} p<.05, \mathrm{CI}=$ Confidence Interval

Table 6 indicates the level of contribution of age, gender and parental choice. The results of regression indicate the three predictors explained $16 \%$ of the variance $\left(R^{2}=.16, F(3,1196)=12.95, p<.05\right)$. It was found that gender significantly predicted the life satisfaction $(\mathrm{B}=11.98, p<.05)$ as did age $(B=13.65, p<.05)$ and parental choice $(B=-9.33, p<.05)$. However, family system, academic achievement and socioeconomic status did not predict life satisfaction.

Stepwise Regression to Assess the Predictors of Life Satisfaction (N=200)

Table 6

\begin{tabular}{llllllllllll}
\hline & Model 1 & \multicolumn{3}{c}{ Model 2 } & \multicolumn{3}{c}{ Model 3 } & & 95\% CI \\
\hline Predictors & $B$ & $S E$ & $\beta$ & $B$ & $S E$ & $\beta$ & $B$ & $S E$ & $\beta$ & $L L$ & $U L$ \\
Constant & 13.34 & 4.52 & & 26.26 & 6.04 & & 39.71 & 7.33 & {$[4.51,22.34]$} \\
Gender & 11.98 & 2.86 & .28 & 13.61 & 2.84 & .32 & 12.89 & 2.79 & .30 & {$[7.37,18.41]$} \\
Age & & & & 13.65 & 4.38 & .21 & 13.87 & 4.29 & .21 & {$[22.33,5.43]$} \\
$\begin{array}{l}\text { Parental } \\
\text { Choice }\end{array}$ & & & & & & & & -9.33 & 3.03 & -.20 & {$[-15.37,-3.41]$} \\
\hline
\end{tabular}

Step 1: $F(1,198)=17.54, p<.05$. Step 2: $F(2,197)=14.01, p<.05$. Step 3: $F(3,196)=12.95, \mathrm{p}<.05$, $C I=$ Confidence Interval 
In terms of the current investigation, Preacher and Hayes (2008) bootstrapping method was used for the purpose of testing and observing whether parental choice mediated the association between academic achievement and life satisfaction.

The core assumption of mediation analysis is to assess whether a significant relationship is seen between the predictor and the outcome variable. Correlation Matrix (See table of correlations) had shown that all variables being researched were significantly associated.

Path $\mathrm{c}$ in the table shows the predictive association between academic achievement as the independent variable and life satisfaction as the dependent variable without controlling for parental choice as the mediator. There was a significant predictive relationship between academic achievement as the independent variable and life satisfaction as the dependent variable without controlling the effects of sleep quality $(B=-.16, p<.001)$.

Path " $a$ " shows relationship between academic achievement as the predictor variable and parental choice as the mediator. This path has shown that depression was significantly associated with the mediator variable i.e. parental choice $(B=.09, p<.001)$.

Path $\mathrm{b}$ in the table shows parental choice as the predictor of life satisfaction. There was a significant predictive relationship that was seen $(B=-.54, p<.001)$.

The path c' (c prime path) shows the association between academic achievement as the independent variable and life satisfaction as the dependent variable when controlling for the mediator (parental choice). If depression has no effect on psychological wellbeing and c' model is no more significant, then it can be said that there is complete mediation. However, in this case, a decrease in the level of association was seen between the relationship of depression (IV) and psychological wellbeing (DV) which is an indication of partial mediation $(B=$ $-.12, p<.001)$.

\section{Mediating Effect of Parental Choice on the Association between Academic Achievement and Life Satisfaction $(\mathbf{N}=\mathbf{2 0 0})$}

Table 7

\begin{tabular}{llll}
\hline Measures & $B$ & $S E$ & $p$ \\
\hline Step 1 (Path c) & & & .000 \\
$\quad$ Outcome: LS & & .02 & \\
$\quad$ Acad Ach & -.16 & & .000 \\
Step 2 (Path a) & & .01 & \\
$\quad \begin{array}{l}\text { Outcome: PC } \\
\text { Acad Ach }\end{array}$ & .09 & & .000 \\
Step 3 (Path b) & & .04 & \\
$\quad$ Outcome: LS & & & .000 \\
$\quad$ PC & -.54 & &
\end{tabular}

Note. Acad Ach=Academic Achievement, $\mathrm{PC}=$ Parental Choice, $\mathrm{LS}=$ Life Satisfaction, $\mathrm{B}=$ standardized coefficient. ${ }^{*} p<.05, * * p<.01 . * * * p<.001$

\section{Discussion And Conclusion}

The purpose of the present study was to investigate the relationship between academic achievement and life satisfaction and how parental choice influenced this association for medical students. Also, the study was focused on assessing gender differences among the participants. Another aim of the study was to assess the mediation of parental choice between the relationship of academic achievement and life satisfaction. The findings of the present study have resulted in a number of insights.

Firstly, it was hypothesized that there would be a significant relationship between academic achievement and life satisfaction. The results of the present study have confirmed this hypothesis which is an indication that medical student's academic achievement does have an association with their level of life satisfaction. There is also a considerable amount of literature that has supported these findings. Numerous researches and findings support a significant, positive connection among life satisfaction and academic achievement for students (Lent, Brown, \& Larkin, 1987; Locke, Frederick, Lee, Bobko, 1984; timber \& Locke, 1987). Lent, Brown, Larkin (1987) stated that those, who have excessive self-efficacy scores and high scholastic aptitudes, have a tendency to attain more, favorable academic outcomes than those who have lower self-efficacy and aptitude rankings. 
Previous studies have found that parental choice is a predictive of university grades and their level of life satisfaction. Having belief that an individual would carry out successfully in a given direction predicts actual a hit performance in that direction. Lent, Brown and Larkin (1987) discovered "parental choice introduced large precise variance past measures of goal ability and fulfillment in predicting next instructional overall performance and endurance".

There are also other studies that have supported the finding that academic achievement and life satisfaction are significantly related with one another. Redman, Saltman, Straton Young and Paul (2004) studied the determinants of career choices and life satisfaction among medical students. It was found that forced parental choice was more impactful and prevalent for female medical students in comparison to men. It was also found that forced parental choice negatively impacted the relationship between academic achievement and life satisfaction for the students. Keeping in view the findings, it has been confirmed that academic achievement and life satisfaction are closely related to one another.

Secondly, it was hypothesized that there would be significant gender differences among medical students in terms of academic achievement and life satisfaction. However, the results of the present study did not support this hypothesis. In relevance to the findings, this hypothesis has been rejected. There is evidence in the past literature that males and female medical students do tend to differ from one another in terms of academic achievement and life satisfaction (Lepp, Barkley \& Karpinski, 2014).

Strayhorn (2014) have also reported that males tend to scored higher than females on academic achievement. Other studies have shown that males and female medical students and those belonging to other fields do not tend to differ from one another in relevance to academic achievement and life satisfaction (Jenkins, Belanger, Boals, Connally \& Duron, 2013; Schmitt, Branscombe, Postmes\& Garcia, 2014).

Thirdly, it was hypothesized that parental choice would mediate the relationship between academic achievement and life satisfaction. The findings of the present study have conformed the findings of the present study. There is also research evidence to establish that parental choice does have an impact on the level of academic achievement and life satisfaction among students.

Roeser and Peck (2009) had explored the role of self-awareness, meta-cognition, parenting and other demographic factors that influence academic achievement among students. The results had shown that parental choice was a significant mediator between academic achievement and life satisfaction for students. Also, parents who forced their children to pursue medical careers without providing them with complete guidance and support negatively impacted academic achievement of students. It was found that conscious and willful intent of students coupled with parental support is important in terms of influencing the self-esteem of students. It is important to consider that academic performance of students and their sense of academic achievement is determined on the basis of a number of measures including self-efficacy, self-awareness, Meta cognitive awareness etc.

These factors have a combined impact on the academic performance and educational attainment of students. There is also other research evidence that has shown that parental choice does mediate the relationship between academic achievement and life satisfaction. Sui-Chu and Willms (2006) studied the role of parental involvement in terms of influencing academic achievement among students. It was found that parents who engaged in excessive involvement and forced their children to pursue their own preferential careers negatively impacted their achievement.

It is critical to note that the results of the present study have provided new insights about the role of parental choice in terms of impacting academic achievement and life satisfaction of medical students. The studies that were explored on this area have also shown that the role of parents and their amount of interference in the career choices of their children is an important determinant and mediator of the level of academic achievement and life satisfaction among the medical graduates. It has also been found that for medical students, there are a number of factors that influence career choices of students.

There are an infinite number of learning experiences that impact career choice. However, one major factor in this regard is parental choice. It has been found that in a large number of cases, parental choice is forced upon students. This is mainly because of the fact that parents are the ones who finance the education of their children in a large number of cases. This fact is equally true for both developed and developing regions. Also, parental choice is less important for those students who are able to finance their own education. Secondly, pursuing a profession in the domain of medicine is a tough decision. For medical students, parental choice becomes important and a determining factor at times when they are not able to take a decision on their own.

\section{Limitations}

The limitations of the study are as follow:

i. The sample was limited to medical students alone keeping in view the focus of the study. However, a cross comparison between other fields with medical students would have provided a more clearer picture

ii. The sample was limited to a few medical colleges of Lahore due to lack of access to other institutions 
iii. The study has shown that forced parental choice is important and that it does mediate the relationship between academic achievement and life satisfaction. However, the exact mechanism through which this choice impacts academic achievement and life satisfaction is not clear. This can be better assessed using qualitative investigations

iv. The study does not provide causal explanations about the role of parental choice. The researcher had planned to establish causal relations but was not able to do due to the limitations of the research design

\section{Implications}

The implications of the study are as follow:

i. The study has provided insights about how important parental choice is for influencing career development, academic achievement and life satisfaction of students.

ii. The study has raised the need of more support and encouragement for medical students from the side of their parents. For students who were forced to pursue medical profession, low levels of life satisfaction and academic achievement were seen. Forced parental choice negatively predicted academic achievement and life satisfaction. For this reason, it is important for institutions to provide more guidance and support to students.

iii. There is a need for increasing the emphasis on career counseling and psychological support for medical students. In addition, the findings of the study have raised questions for the overall education system in Pakistan. The increasing amount of interference from parents, their lack of support for their children, the large amount of pressure that medical students face and other related factors have raised the need of multiple interventions.

iv. Psychologists, media personnel, social workers, educationists and other individuals need to work together for providing more awareness to parents and students on this area.

v. A joint effort in this regard can result in positive benefits in terms of increasing life satisfaction and academic achievement among medical students.

\section{Conclusion}

It can be concluded that forced parental choice does have an influence on academic achievement and life satisfaction among medical students. It was also found that academic achievement and life satisfaction are significantly related to one another. Also, there are no gender differences among participants on these constructs. It can be concluded that forced parental choice is an important determinant of academic achievement and life satisfaction.

The influence is mainly negative and does raise a wide range of questions about how and why parents force their children to pursue professions without their consent or without keeping their interests into focus. It can also be concluded that parental support, parental involvement and choice are important factors that have a considerable amount of influence on academic achievement and life satisfaction.

\section{Recommendations}

Recommendations of study are as follows:

i. More qualitative studies need to be conducted on this area in order to gain detailed insights about the role of parental involvement and forced parental choice

ii. Studies should be done using larger and more diverse sample sizes using students from multiple universities and fields

iii. More studies should be done on this area in order to increase the awareness of parents and students on this area and to inspire government, educational and media bodies to play their roles

iv. Overall, educational institutions, governmental bodies, media channels, social workers, psychologists and educationists need to work together to bring about a change in the level of academic achievement and life satisfaction among medical students

\section{References}

Burnam, M. A., Hough, R. L., Escobar, J. I., Karno, M., Timbers, D. M., Telles, C. A., \& Locke, B. Z. (1987). Six-month prevalence of specific psychiatric disorders among Mexican Americans and non-Hispanic whites in Los Angeles. Archives of General Psychiatry, 44(8), 687-694.

Casas, F., Bălțătescu, S., Bertran, I., González, M., \&Hatos, A. (2013). School satisfaction among adolescents: Testing different indicators for its measurement and its relationship with overall life satisfaction and subjective well-being in Romania and Spain. Social Indicators Research, 111(3), 665-681.

Chak-keung Wong, S., \& Jing Liu, G. (2010). Will parental influences affect career choice? Evidence from hospitality and tourism management students in China. International Journal of Contemporary Hospitality Management, 22(1), 82-102. 
Costa, S., Soenens, B., Gugliandolo, M. C., Cuzzocrea, F., \&Larcan, R. (2015). The mediating role of experiences of need satisfaction in associations between parental psychological control and internalizing problems: A study among Italian college students. Journal of Child and Family Studies, 24(4), 1106-1116.

Crede, J., Wirthwein, L., McElvany, N., \&Steinmayr, R. (2015). Adolescents' academic achievement and life satisfaction: the role of parents' education. Frontiers in psychology, 6.

Ferry, T. R., Fouad, N. A., \& Smith, P. L. (2000). The role of family context in a social cognitive model for career-related choice behavior: A math and science perspective. Journal of Vocational Behavior, 57(3), 348-364.

Gerdes, H., \& Mallinckrodt, B. (1994). Emotional, social, and academic adjustment of college students: A longitudinal study of retention. Journal of Counseling \& Development, 72(3), 281-288.

Hofmann, W., Luhmann, M., Fisher, R. R., Vohs, K. D., \&Baumeister, R. F. (2014). Yes, but are they happy? Effects of trait self-control on affective well-being and life satisfaction. Journal of Personality, 82(4), 265-277.

Jayawickreme, E., Tsukayama, E., \&Kashdan, T. B. (2017). Examining the effect of affect on life satisfaction judgments: A within-person perspective. Journal of Research in Personality, 68, 32-37.

Jenkins, S. R., Belanger, A., Connally, M. L., Boals, A., \&Durón, K. M. (2013). First-generation undergraduate students' social support, depression, and life satisfaction. Journal of College Counseling, 16(2), 129142.

Jenkins, S. R., Belanger, A., Connally, M. L., Boals, A., \&Durón, K. M. (2013). First-generation undergraduate students' social support, depression, and life satisfaction. Journal of College Counseling, 16(2), 129142.

Jiang, X. U., Huebner, E. S., \& Hills, K. J. (2013). Parent attachment and early adolescent's life satisfaction: the mediatting effect of hope. Psychology in the Schools, 50(4), 340-352.

Lent, R. W., Brown, S. D., \& Larkin, K. C. (1987). Comparison of three theoretically derived variables in predicting career and academic behavior: Self-efficacy, interest congruence, and consequence thinking. Journal of counseling psychology, 34(3), 293.

Lepp, A., Barkley, J. E., \&Karpinski, A. C. (2014). The relationship between cell phone use, academic performance, anxiety, and satisfaction with life in college students. Computers in Human Behavior, 31, 343-350.

Locke, E. A., Frederick, E., Lee, C., \&Bobko, P. (1984). Effect of self-efficacy, goals, and task strategies on task performance. Journal of applied psychology, 69(2), 241.

Mallard, A. G., Lance, C. E., \&Michalos, A. C. (2017). Culture as a moderator of overall life satisfaction-Life facet satisfaction relationships. In Connecting the Quality of Life Theory to Health, Well-being and Education(pp. 59-79). Springer International Publishing.

Otoole, L. I. N. D. A. (2009). Understanding Individual Patterns of Learning: implications for the well-being of students. European Journal of Education, 43(1), 71-86.

Redman, S., Saltman, D., Straton, J., Young, B., \& Paul, C. (2004). Determinants of career choices among women and men medical students and interns. Medical Education, 28(5), 361-371.

Röcke, C. (2016). Life Satisfaction. The Encyclopedia of Adulthood and Aging.

Roeser, R. W., \& Peck, S. C. (2009). An education in awareness: Self, motivation, and self-regulated learning in contemplative perspective. Educational psychologist, 44(2), 119-136.

Saha, N., \&Karpinski, A. C. (2016). The influence of social media on international students' global life satisfaction and academic performance. Campus Support Services, Programs, and Policies for International Students, 57.

Schmitt, M. T., Branscombe, N. R., Postmes, T., \& Garcia, A. (2014). The consequences of perceived discrimination for psychological well-being: A meta-analytic review. Psychological Bulletin, 140(4), 921.

Strayhorn, T. L. (2014). What role does grit play in the academic success of black male collegians at predominantly white institutions?. Journal of African American Studies, 18(1), 1-10.

Sui-Chu, E. H., \&Willms, J. D. (2006). Effects of parental involvement on college achievement. Sociology of education, 126-141.

Varela, J. J., Zimmerman, M. A., Ryan, A. M., Stoddard, S. A., Heinze, J. E., \& Alfaro, J. (2017). Life Satisfaction, School Satisfaction, and School Violence: A Mediation Analysis for Chilean Adolescent Victims and Perpetrators. Child Indicators Research, 1-19.

Zahedani, Z. Z., Rezaee, R., Yazdani, Z., Bagheri, S., \&Nabeiei, P. (2016). The influence of parenting style on academic achievement and career path. Journal of advances in medical education \& professionalism, 4(3), 130. 


\section{(2)}

\section{APPENDICES}

\section{Demographic Form}

Age

Gender

SES:

Education

Marital status

Grades

College: Government/Private

\section{Informed Consent Form}

i. I voluntarily agree to participate in this research study.

ii. I understand that even if I agree to participate now, I can withdraw at any time or refuse to answer any question without any consequences of any kind.

iii. I have had the purpose and nature of the study explained to me in writing and I have had the opportunity to ask questions about the study.

iv. I understand that I will not benefit directly from participating in this research.

v. I understand that all information I provide for this study will be treated confidentially.

vi. I understand that in any report on the results of this research my identity will remain anonymous.

vii. I understand that I am free to contact any of the people involved in the research to seek further clarification and information.

Signature 


\section{QUESTIONNARE}

\section{SWLS (Satisfaction with life scale)}

\section{Instructions}

Below are five statements that you may agree or disagree with. Using the 1 - 7 scale below, indicate your agreement with each item by placing the appropriate number on the line preceding that item. Please be open and honest in your responding.

\begin{tabular}{|l|l|l|l|}
\hline $7=$ Strongly agree & $6=$ Agree & $5=$ Slightly agree & $4=$ Neither agree nor disagree \\
\hline $\begin{array}{l}3=\text { Slightly } \\
\text { disagree }\end{array}$ & $2=$ Disagree & $\begin{array}{c}1=\text { Strongly } \\
\text { disagree }\end{array}$ & \\
\hline
\end{tabular}

\begin{tabular}{|c|l|l|l|l|c|c|c|c|}
\hline Item no & Statement & 1 & 2 & 3 & 4 & 5 & 6 & 7 \\
\hline 01 & In most ways my life is close to my ideal & & & & & & & \\
\hline 02 & The conditions of my life are excellent & & & & & & \\
\hline 03 & I am satisfied with my life & & & & & \\
\hline 04 & $\begin{array}{l}\text { So far I have gotten the important things I want in } \\
\text { life } \\
\text { If I could live my life over, I would change almost } \\
\text { nothing }\end{array}$ & & & & & & & \\
\hline 05 & & & & & \\
\hline
\end{tabular}

\section{ACADEMIC MOTIVATION SCALE (AMS-C 28) COLLEGE (CEGEP)} VERSION

\section{Instructions}

This scale contains 28 items assessed on a 7-point scale.

WHY DO YOU GO TO COLLEGE (CEGEP)?

Using the scale below, indicate to what extent each of the following items presently corresponds to one of the reasons why you go to college (CEGEP)? 


\begin{tabular}{|c|c|c|c|}
\hline $7=$ Strongly agree & $6=$ Agree & $5=$ Slightly agree & $\begin{array}{c}4=\text { Neither agree nor } \\
\text { disagree }\end{array}$ \\
\hline $3=$ Slightly disagree & 2 = Disagree & $\begin{array}{c}1=\text { Strongly } \\
\text { disagree }\end{array}$ & \\
\hline
\end{tabular}

\begin{tabular}{|c|c|c|c|c|c|c|c|c|}
\hline Item \# & Statements & 1 & 2 & 3 & 4 & 5 & 6 & 7 \\
\hline 01 & $\begin{array}{l}\text { Because with only a high-school degree I would not find a } \\
\text { high-paying job later on }\end{array}$ & & & & & & & \\
\hline 02 & $\begin{array}{l}\text { Because I experience pleasure and satisfaction while } \\
\text { learning new things }\end{array}$ & & & & & & & \\
\hline 03 & $\begin{array}{l}\text { Because I think that a college, education will help me better } \\
\text { prepare for the career I have chosen. }\end{array}$ & & & & & & & \\
\hline 04 & $\begin{array}{l}\text { For the intense feelings I experience when I am } \\
\text { communicating my own ideas to others }\end{array}$ & & & & & & & \\
\hline 05 & $\begin{array}{l}\text { Honestly, I don't know; I really feel that I am wasting my } \\
\text { time in school }\end{array}$ & & & & & & & \\
\hline 06 & $\begin{array}{l}\text { For the pleasure I experience while surpassing myself in my } \\
\text { studies }\end{array}$ & & & & & & & \\
\hline 07 & $\begin{array}{l}\text { To prove to myself that I am capable of completing my } \\
\text { college (CEGEP) degree }\end{array}$ & & & & & & & \\
\hline 08 & In order to obtain a more prestigious job later on. & & & & & & & \\
\hline 09 & $\begin{array}{l}\text { For the pleasure I experience when I discover new things } \\
\text { never seen before }\end{array}$ & & & & & & & \\
\hline 10 & $\begin{array}{l}\text { Because eventually it will enable me to enter the job market } \\
\text { in a field that I like }\end{array}$ & & & & & & & \\
\hline 11 & $\begin{array}{l}\text { For the pleasure that I experience when I read interesting } \\
\text { authors }\end{array}$ & & & & & & & \\
\hline 12 & $\begin{array}{l}\text { I once had good reasons for going to college, however, now I } \\
\text { wonder whether I should continue. }\end{array}$ & & & & & & & \\
\hline 13 & $\begin{array}{l}\text { For the pleasure that I experience while I am surpassing } \\
\text { myself in one of my personal accomplishments }\end{array}$ & & & & & & & \\
\hline
\end{tabular}




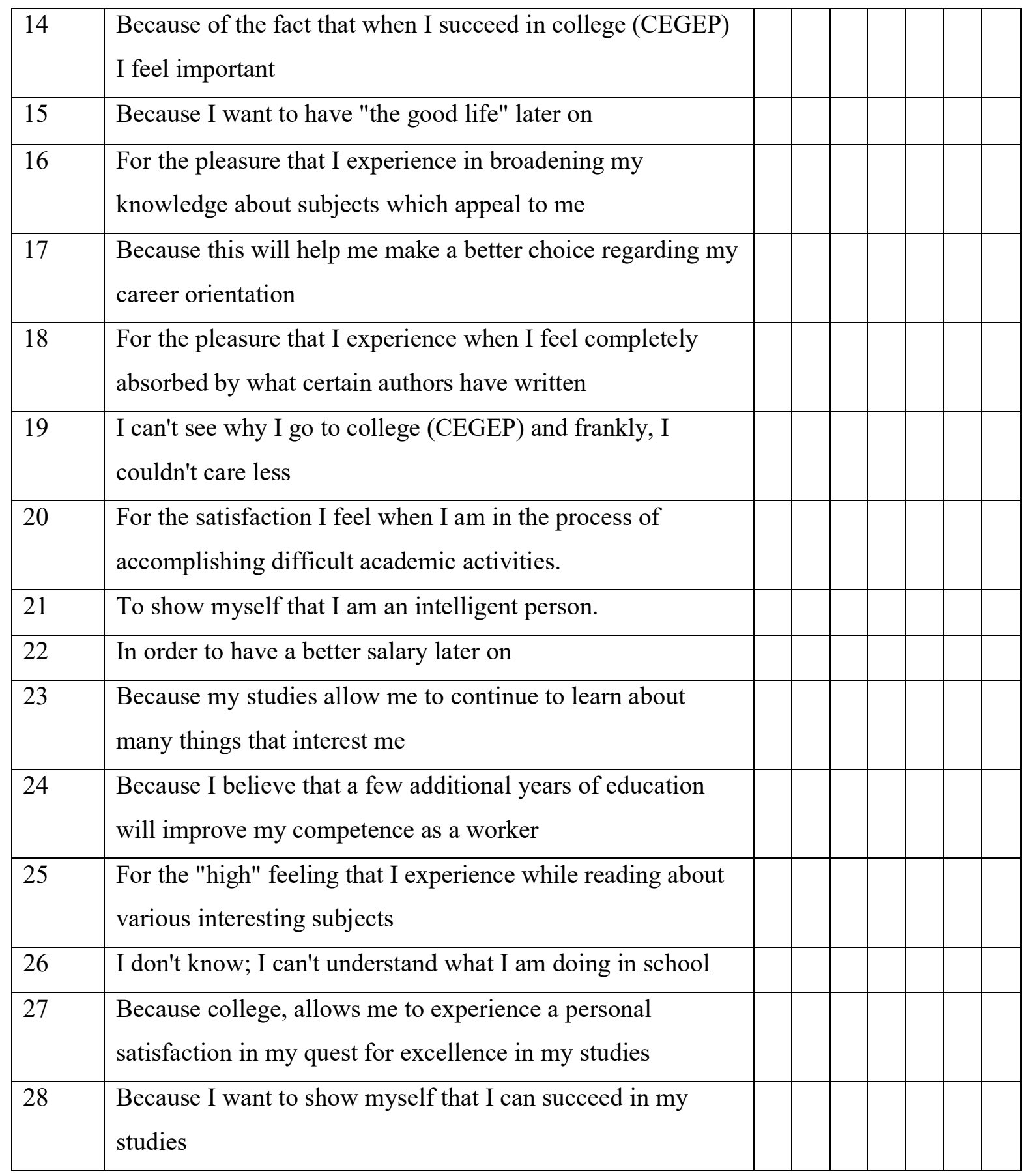

